\title{
Marketing Digital e os Digital Influencers: Breves comentários acerca dessa ferramenta e de sua eficácia na divulgação de bens e serviços
}

André Luis Sant'Anna

\begin{abstract}
Resumo: o marketing digital tem se apresentado como ótima ferramenta para transações no mercado econômico. Um dos motivos dessa importância está relacionado ao aumento significativos das plataformas de comunicação online, para mais de $20 \%$ em 2013, refletindo na desvalorização de revistas e jornais impressos. Nesse novo cenário, com redes sociais, as pessoas tendem a se agruparem em comunidades com interesses semelhantes. Um dos líderes de junção de pessoas em uma mesma comunidade, são os digital influencers (influenciadores digitais), que são verdadeiros formadores de opiniões e tem sido amplamente utilizados como forma de marketing digital. Este artigo discute, com base na literatura especializada, o marketing digital. conclui-se que é fundamental o investimento no marketing digital, para fins de acompanhamento e adequação à era digital, como oportunidade de promoção de marcas e produtos e, fortalecimento de relacionamento com os clientes através dos digital influencers.
\end{abstract}

Palavras-chave: Marketing, Digital influencers, Comunicação.

\section{Digital marketing and digital influencers: Brief comments about this tool and its effectiveness in the dissemination of goods and services.}

\begin{abstract}
Digital marketing has presented itself as a great tool for transactions in the economic market. One of the reasons for this importance is related to the significant increase of online communication platforms, to more than $20 \%$ in 2013 , reflected in the devaluation of magazines and printed newspapers. In this new scenario, with social networks, people tend to cluster in communities with similar interests. One of the leaders of people joining in the same community, are digital influencers, who are true opinion formers and have been widely used as a form of digital marketing. This article discusses, based on specialized literature, digital marketing. it is concluded that the investment in digital marketing is fundamental for the purpose of accompanying and adapting to the digital age, as an opportunity to promote brands and products and strengthen relationships with customers through digital influencers.
\end{abstract}

Keywords: Marketing, Digital influencers, Communication.

\section{Introdução}

No início do século XX, o Marketing surgiu como disciplina voltada para encontrar formas de solucionar os problemas das empresas em relação aos seus processos de distribuição, momento em que era necessário desenvolver um método que possibilitasse chegar aos seus

\footnotetext{
${ }^{1}$ Médico pela Universidade Gama Filho - RJ. Residência em Ortopedia e Traumatologia pelo Hospital Municipal Barata Ribeiro - RJ. Pós Graduação em Biomedicina do Exercício e do Esporte pela Universidade Federal do Ceará - Fortaleza, CE. Acadêmico de Marketing pela faculdade Paraíso - FAP. Juazeiro do Norte-CE. Contato: euamoortopedia@ gmail.com.
} 
consumidores da forma mais eficiente e lucrativa possível. (WILKIE; MOORE, 2003, VARGO; LUSCH, 2004). Logo após, o Marketing passou por diversas transformações que modificaram seus termos, conceitos e objetivos, com escopo de se adaptar e suprir as diversas demandas e necessidades das empresas quanto aos clientes, consumidores e concorrentes.

Essas mudanças direcionaram a disciplina, garantindo sua importância e utilidade para que as empresas conseguissem resolver problemas em diversos setores (LUSCH, 2007, WILKIE; MOORE, 2003), principalmente após a reformulação dos mercados causada pela globalização e constantes inovações tecnológicas, que por possibilitaram um consumo cada vez mais célere, desperta a necessidade de adotar novos canais de comunicação, distribuição e de alcance ao consumidor.

Com base nisso, pode-se definir três principais fases da disciplina: (i) to marketing, momento em que a oferta e capacidade de produção eram pequenos, assim, o objetivo da disciplina era levar os produtos para o mercado, juntando os bens de consumo ao consumidor; (ii) market(ing) to, relacionado a um período em que a oferta e capacidade de produção são maiores, onde a função da disciplina era elaborar um marketing direcionado para os principais clientes; e (iii) market(ing) with, época que envolve um estágio mais avançado dos mercados, em que os serviços dominam o mundo econômico e as empresas precisam tratar seus cliente como um tipo de parceiro que a ajudará na criação e aperfeiçoamento de produtos e serviços (LUSCH, 2007).

Nota-se que hodiernamente o cenário econômico se enquadra na terceira fase, em que os consumidores atuam como parceiros dos produtores, onde, através de um estreitamento de relacionamento, é possível verificar as necessidades, exigências e vontades do consumidor e, assim, direcionar a produção para supri-las.

Nesse contexto, o marketing digital tem se apresentado como ótima ferramenta de auxílio, tendo em vista que a internet ocupa um dos mais importantes meios de transações do mercado econômico ${ }^{1}$. Um dos motivos dessa importância alcançada pelo meio digital, está relacionado ao aumento significativos das plataformas de comunicação online, para mais de

\footnotetext{
${ }^{1}$ À título de exemplo, em 2017, o consumo em plataformas online nos EUA ultrapassou US\$ 100 bilhões, em que o consumo de bens informacionais - livros, revistas e softwares - aumentaram de 25\% para 50\% (ALBUQUERQUE ET AL, 2012). Corroborando com isso, dados apontam que no sítio eletrônico da Amazon.com onde, em 26 de novembro de 2012, houve a compra de cerca de 26,5 milhões de itens no mundo, totalizando um recorde de 306 itens por segundo (CHEREDAR, 2012 ,CLAY, 2012).
} 
20\% em 2013, refletindo na desvalorização de revistas e jornais (Marketing News, maio de 2013, p. 16).

Ademais, considerando os países da Europa, os EUA, Brasil e Índia, cerca de 70\% da população possuem pelos menos uma conta em alguma rede social. Nota-se que essas redes sociais têm impulsionado e estimulado a comunicação e troca de informações entre usuários, razão pela qual a plataforma digital tem sido ferramenta interessante para as empresas, que utilizam desse artifício para se promoverem. Com base nisso, pesquisas realizadas revelam que os gestores que investem nesse tipo de mídia conseguem conquistar o público com mais facilidade, criando fãs leais e um "boca-a-boca" positivo (DE VRIES ET AL, 2012, DHOLAKIA; DURHAM, 2010).

Estima-se que cerca de 32 bilhões de buscas são realizadas mensalmente nos sítios de busca, tal como o Google, e que mais de 50 milhões de tweets são submetidos por dia ao redor do mundo. Como consequência, as marcas perderam o controle sobre as mensagens que antes eram divulgadas como estratégias de divulgação da marca (ALBUQUERQUE ET AL., 2012), já que está divulgação, seja positiva seja negativa, agora está nas mãos dos usuários da internet. Sendo assim, resta notório que o marketing realizado de forma tradicional está em risco.

Sem dúvidas o processo de comunicação vem passando por diversas transformações que têm possibilitado a mudança de uma estrutura baseada em one-to-many (um-para-muitos) para uma pautada em many-to-many (muitos-para-muitos). Essa evolução foi possibilitada pela internet que modificou e facilitou a forma de interação, comunicação e conexão entre as pessoas, assim como entre as empresas e sua clientela. (HOFFMAN; NOVAK, 1996).

Com tantas inovações tecnológicos, deu-se início a era digital, em que quase tudo pode ser realizado por um plano virtual, e não diferente seria em relação as propagandas empresariais. Assim, essa revolução tecnológica implicou na necessidade de aperfeiçoamento dos métodos de propaganda tradicionais (KUMAR; GUPTA, 2016, SCHULTZ, 2016), principalmente devido as empresas terem que aprender a lidar com um público cada vez mais informado e engajado com as mídias sociais e redes virtuais sociais.

Nesse novo cenário de redes sociais, as pessoas tendem a se agruparem em comunidades que lhes dão sensação de pertencimento, sendo este o local onde irão buscar por informações e conexão com outras pessoas com interesses semelhantes. Um dos líderes de junção de pessoas em uma mesma comunidade, são os digital influencers (influenciadores digitais), que são

29 Id on Line Rev. Mult. Psic. V.12, N. 42, Supl. 1, p. 27-40, 2018 - ISSN 1981-1179 Edição eletrônica em http://idonline.emnuvens.com.br/id 
verdadeiros formadores de opiniões e tem sido amplamente utilizados como forma de marketing digital.

Os influenciadores digitais possuem alguma rede social onde reúnem uma gama de seguidores que se identificam de algo que eles divulgam em seus canais virtuais. Assim, as marcas têm se utilizado desses influenciadores para anunciar seus produtos ou serviços, uma vez que pesquisas revelaram que esse tipo de propaganda é capaz de transferir reconhecimento, confiança e respeito pelo anunciado de forma mais eficaz (KUMAR; GUPTA, 2016).

Com base nisso, o presente estudo tem o objetivo de avaliar a evolução do Marketing digital, analisando seus benefícios e identificando os principais desafios enfrentados pelas empresas no uso dessa metodologia; buscando, por fim, busca estudar os influenciadores digitais e os benefícios que eles representam para o marketing digital

\section{As crescentes mídias digitais e os desafios do marketing digital:}

A evolução e expansão das mídias digitais têm representado uma ameaça aos modelos tradicionais de empreendimentos em relação a forma como a empresa cria e fornece seus bens, bem como na forma como elas capturam clientes. Os modelos adotados pelas marcas devem envolver um sistema bem estruturado, onde estão bem definidas os processos e atividades da melhor forma para criar seu valor frente aos clientes e seus parceiros, no entanto, as mudanças ocasionadas pela atual revolução digital têm dificultado a aplicação dessas estratégias e a criação de valor (SORESCU ET AL, 2011, p. 4).

A era digital tem interferido no consumo como um todo, de forma que o futuro do marketing é investir na plataforma online de sua marca. Assim, oferecer a possibilidade dos clientes pesquisarem e comprarem online requer que as empresas modifiquem suas estratégias de atuação. Isso porque, apesar de apenas cerca de 5\% das vendas das empresas serem provenientes de compras, o marketing digital atua como uma forma de divulgação da marca e atração de novos clientes.

Nesse contexto, pode-se dizer que um dos desafios mais importantes a ser enfrentado pelo marketing digital é a capacidade de gerar percepções positivas em seus consumidores acerca do bem ou produto disponibilizado. Assim, o acompanhamento do percurso da compra

30 Id on Line Rev. Mult. Psic. V.12, N. 42, Supl. 1, p. 27-40, 2018 - ISSN 1981-1179 Edição eletrônica em http://idonline.emnuvens.com.br/id 
e interação com os clientes tornou-se ferramenta importante otimizar campanhas de publicidade e o marketing digital, sendo de suma importância a análise das informações que os clientes buscam e as comparações que realizam antes de realizar sua compra (DAVENPORT, 2006). Contudo, mais de $80 \%$ das empresas ainda não possuem acesso, tampouco analisam esses dados para fins de desenvolver sua capacidade de vincular os clientes.

A crescente globalização veio acompanhada de forte digitalização e informatização dos meios, o que trouxe importantes desafios para o marketing. O mercado cada vez mais complexo demanda rápidas mudanças do meio empresarial, e não diferente do marketing, razão pela qual houve a necessidade de adaptação as mudanças rapidamente, conforme ocorriam.

Atualmente, os principais canais digitais são as home pages das empresas, e-mail e mídias sociais $^{2}$, e consistem nas áreas que possibilitam maior probabilidade de crescimento para empresas, motivo pelo qual espera-se que as empresas invistam cada vez mais nos canais de interação com os clientes, tendo em vista que tem demonstrado ser uma ótima estratégia de Marketing.

A importância da interação com os clientes, bem como a disponibilização de novas ferramentais digitais de serviço - como no caso dos aplicativos de bancos-, é uma das mudanças mais significativas possibilitada pelas inovações da atualidade. Além dessa, a crescente capacidade de alcançar novos segmentos e clientes com o uso da mídia digital, aparece mais um dos muitos impactos positivos que a digitalização da mídia e da sociedade proporcionou ao marketing empresarial.

Dados apontam que cerca de $90 \%$ dos consumidores buscam por avaliações e críticas online antes de realizar a compra de um produto ou a utilização de um serviço, lendo no mínimo quatro avaliações, de onde a maioria advém de opiniões formuladas por outros compradores (GODES; SILVA, 2012, KEE, 2008). Como se pode deduzir, essas críticas divulgadas nas plataformas online são de suma importância nas decisões de compra. Assim, os conteúdos divulgados nas mídias digitais demonstram ter mais influenciadores do que aqueles criados pela publicidade, o que deve ser levado em consideração pelo marketing para fins de criar um maior envolvimento do cliente (VAN DOORN ET AL, 2010).

\footnotetext{
${ }^{2}$ Ressalte-se que com a popularização dos smartphones, a revolução da internet tornou-se ainda mais significativa (HUSSON ET AL, 2013), o que sugere que as empresas devam investir nas estratégias de marketing voltado para esse público.
}

31 Id on Line Rev. Mult. Psic. V.12, N. 42, Supl. 1, p. 27-40, 2018 - ISSN 1981-1179 Edição eletrônica em http: ://idonline.emnuvens.com.br/id 
Assim, blogs, canais no Youtube, grupos de discussão, dentre outros, estão sendo largamente utilizados para classificar produtos e serviços, bem como para a divulgação de uma boa ou má experiência obtida pelo consumidor sobre a sua tomada de decisão e comportamento de compra e pós-compra (MAYZLIN; YOGANARASINHAN, 2012, ONISHI; MANCHANDA, 2012). Com isso, a revolução digital, apesar de favorecer a divulgação de produtos de uma forma mais ampla e rápida, possui diversos desafios a serem enfrentados pela empresa.

Nesse cenário, pesquisa realizada por Peter Leeflang, Peter Verhoef, e Tjark Freundt (2014, p. 2), com os principais cientistas de marketing clientes da McKinsey e especialistas da McKinsey, apontaram três principais desafios enfrentados pelo marketing digital, sendo eles: (i) a capacidade de gerar percepções positivas dos clientes; (ii) gerir e preservar a reputação da marca nesse meio de mídias digitais; e (iii) alcançar a eficácia possibilitada pelo marketing digital. Com base nisso, os mesmos autores apontam as três principais vantagens de se enfrentar esses desafios da mídia digital, quais sejam: (i) encontrar profissionais qualificador para gerir o marketing digital da empresa; (ii) remodelação das estruturas da empresa com base nas tendências digitais da atualidade, tornando-a mais segura na tomada das decisões; e (iii) elaboração de métricas digitais acionáveis; todas capazes de melhorar o alcance e desemprenho da marca.

Nesse diapasão, as mídias digitais têm representado um grande desafio para as empresas, podendo ser representado pelas seguintes principais tensões de mercado a serem enfrentadas pela equipe de marketing:

\begin{tabular}{|c|c|c|c|}
\hline Categorias & $\begin{array}{l}\text { Tensão de } \\
\text { mercado }\end{array}$ & Desafio & Descrição \\
\hline \multirow{3}{*}{$\begin{array}{l}\text { 1. Estratégia de negócios } \\
\text { e visão dos clientes sobre a } \\
\text { marca }\end{array}$} & $\begin{array}{l}\text { 1. Revolução } \\
\text { digital }\end{array}$ & $\begin{array}{c}\text { Abraçar } v s . \\
\text { defender }\end{array}$ & $\begin{array}{c}\text { O crescimento das } \\
\text { mídias digitais tem } \\
\text { ameaçado os modelos } \\
\text { empresariais da } \\
\text { atualidade. }\end{array}$ \\
\hline & $\begin{array}{l}\text { 2. Visão dos } \\
\text { clientes }\end{array}$ & $\begin{array}{l}\text { Diferenciador } v s . \\
\quad \text { higiene }\end{array}$ & $\begin{array}{c}\text { A necessidade de } \\
\text { causar percepções. } \\
\text { positivas nos } \\
\text { consumidores para fins } \\
\text { de se tornar mais } \\
\text { competitivo no } \\
\text { mercado. }\end{array}$ \\
\hline & 3. Concorrência & $\begin{array}{l}\text { Processamento de } \\
\text { dados vs. } \\
\text { criatividade } \\
\end{array}$ & $\begin{array}{c}\text { Excesso de confiança } \\
\text { nos dados concretos } \\
\text { pode prejudicar a }\end{array}$ \\
\hline
\end{tabular}

32 Id on Line Rev. Mult. Psic. V.12, N. 42, Supl. 1, p. 27-40, 2018 - ISSN 1981-1179 Edição eletrônica em http://idonline.emnuvens.com.br/id 


\begin{tabular}{|c|c|c|c|}
\hline & & & $\begin{array}{c}\text { criatividade e } \\
\text { desenvolvimento de } \\
\text { inovações. }\end{array}$ \\
\hline \multirow{5}{*}{$\begin{array}{l}\text { Operações de entrada } \\
\text { e de execução no mercado }\end{array}$} & 4. Mídia social & $\begin{array}{l}\text { Engajamento do } \\
\quad \text { cliente } v s . \\
\text { Serviço ao cliente }\end{array}$ & $\begin{array}{c}\text { Acompanhar a } \\
\text { reputação da marca é } \\
\text { mais difícil no atual } \\
\text { cenário de mídias } \\
\text { digitais. }\end{array}$ \\
\hline & $\begin{array}{l}\text { 5. Oportunidades } \\
\text { online }\end{array}$ & $\begin{array}{l}\text { Jovens } v s . \text { os } \\
\text { demais }\end{array}$ & $\begin{array}{l}\text { O marketing digital } \\
\text { negligencia ao visar } \\
\text { apenas os clientes } \\
\text { jovens, esquecendo dos } \\
\text { grupos etários mais } \\
\text { velhos. }\end{array}$ \\
\hline & $\begin{array}{l}\text { 6. Transparência } \\
\text { do preço }\end{array}$ & $\begin{array}{l}\text { Liberdade } v s \text {. } \\
\text { controle }\end{array}$ & $\begin{array}{c}\text { Ferramentas de } \\
\text { comparação de preços } \\
\text { limita a liberdade das } \\
\text { empresas de definirem } \\
\text { seus preços. }\end{array}$ \\
\hline & $\begin{array}{l}\text { 7. Interações } \\
\text { automatizadas }\end{array}$ & $\begin{array}{l}\text { Produtividade } v s \text {. } \\
\text { destrutividade }\end{array}$ & $\begin{array}{c}\text { A automação de } \\
\text { serviços e interações } \\
\text { virtuais com do cliente } \\
\text { podem gerar } \\
\text { insatisfação e } \\
\text { diminuição do valor da } \\
\text { marca. }\end{array}$ \\
\hline & 8. Métricas & $\begin{array}{l}\text { Expansivo } v s . \\
\quad \text { estável }\end{array}$ & $\begin{array}{l}\text { Avaliar a eficácia do } \\
\text { marketing digital é } \\
\text { difícil, visto que não é } \\
\text { possível comparar as } \\
\text { plataformas virtuais e } \\
\text { as tradicionais. }\end{array}$ \\
\hline \multirow{2}{*}{$\begin{array}{l}\text { 3. Organizacional e } \\
\text { corpo empresarial } \\
\text { capacitado }\end{array}$} & $\begin{array}{l}\text { 9. Ausência de } \\
\text { pessoas } \\
\text { talentosas }\end{array}$ & $\begin{array}{l}\text { Atualização } \\
\text { necessária vs. } \\
\text { mudança } \\
\text { fundamental }\end{array}$ & $\begin{array}{l}\text { Os departamentos de } \\
\text { marketing enfrentam } \\
\text { problemas em } \\
\text { encontrar pessoas } \\
\text { capacitadas para tanto. }\end{array}$ \\
\hline & 10. Organização & $\begin{array}{l}\text { Funcional } v s . \\
\text { integrativo }\end{array}$ & $\begin{array}{l}\text { As atividades de } \\
\text { marketing tem sido um } \\
\text { grande desafio em } \\
\text { razão de ser uma } \\
\text { atividade integrativa. }\end{array}$ \\
\hline
\end{tabular}

Fonte: ALBUQUERQUE ET AL, 2012, p. 4 (tradução nossa)

Nota-se que o fundamental é que as empresas analisem essas tensões de mercado buscando compreendê-las, avaliando a forma como elas interferem em seus negócios, e elaborar as melhores estratégias para reagir a casa uma dessas tensões; isto porque todas elas exigem uma resposta do marketing, seja por meio dedo desenvolvimento ou aprimoração das plataformas digitais de mídia social, ou pela adoção de estratégia mais ostensiva nas lojas físicas. 


\section{Os Digital Influencers, Marketing e Publicidade.}

Hodiernamente nas redes sociais, as pessoas têm afetado umas às outras principalmente por meio de influências digitais e sociais, seja de forma conscientes ou não, ativa ou passivamente (ECK VAN; JAGER; LEEFLANG, 2011). As mídias sociais digitais consistem em aplicativos da internet que possibilitam a criação e a troca de conteúdos (KAPLAN; HAENLEIN, 2010, p. 61), onde os consumidores divulgam suas avaliações pessoais sobre bens e serviços utilizados, sendo uma forma de boca-a-boca (CHEN, FAY; WANG, 2011). Nesse cenário, o boca-a-boca tem se revelado ferramenta importante, sendo uma forma de manifestação de influência social que em conjunto com as mídias digitais configuram método útil e eficaz de estímulo ao consumo e verificação das opiniões dos clientes com a marca.

Aqueles que apoiam o uso das mídias sociais para a promoção de uma marca, veem isso como forma de agregar valor e criar conteúdo para seus clientes, com vistas a moderar possível sentimento negativo e a estimular críticas positivas. Ademais, consiste em meio que facilita a interação com o consumidor, o que possibilita o desenvolvimento de uma conexão com os mesmos. Por outro lado, é potencialmente perigoso, pois um cliente enfurecido é capaz de influenciar os demais.

Assim, em um meio de mídias sociais, os clientes tanto podem ser criadores quanto destruidores de valores para uma empresas (VERHOEF ET AL., 2013; VERHOEF ET AL, 2010), o que faz com que o ambiente do marketing digital seja algo desafiador para as empresas, visto que estas estão constantemente lutando para gerir da melhor forma possível esse meio, principalmente em razão do patente contraste com os métodos tradicionais de marketing.

Nesse diapasão, deve-se ressaltar que há uma distinção importante no marketing digital, sendo um de iniciativa das empresas, por meio do uso de websites e comunidades nas redes sociais; e aquele iniciado pelos clientes, com o uso de blogs, vídeos, críticas, dentre outros (DE VRIES ET AL, 2012). Esses últimos têm alcançado grande importância, tendo em vista que os consumidores tendem a não confiar nas publicidades elaboradas pelas próprias marcas (NIELSEN, 2007), sendo uma forma eficiente para criar confiança e conquistar novos públicos, de forma célere e com menor custo.

34 Id on Line Rev. Mult. Psic. V.12, N. 42, Supl. 1, p. 27-40, 2018 - ISSN 1981-1179 Edição eletrônica em http://idonline.emnuvens.com.br/id 
Dentre os diversos métodos de marketing digital, encontra-se os digital influencers (influenciadores digitais), que são definidos como formadores virtuais de opinião, que apresentam um produto ou marca para determinado público alvo, com o objetivo de persuadilos a adquirir o bem ou utilizar do serviço. Sendo assim, pode-se dizer que os influenciadores digitais são uma forma de divulgação que une o marketing da empresa com aquele realizado pelos clientes, já que eles recebem produtos e divulgam seus parecerem sobre o mesmo.

Os influenciadores digitais podem ser instituições ou pessoas que inspiram outros indivíduos, despertando o comportamento consumerista semelhante ao da pessoa/instituição tida como referência (FLYNN; GOLDSMITH; EASTMAN, 1996). Com base nisso, pesquisa realizada por Lyons e Henderson (2005), revelou que as pessoas participantes do grupo do influenciador, aderem quase de forma imediata ao consumo de um bem ou serviço divulgado, devido a busca por inovação, a curiosidade, bem como a tendência de exploração.

Sabe-se que, em regra, a empresa utiliza de blogs e websites, presentes em plataformas virtuais, para divulgar seus produtos ou serviços e conteúdos, por meio de publicações frequentes e organizadas, com o uso de imagens e textos (CASTRO; SANTOS, 2015). Contudo, o uso do poder dos influenciadores digitais tem sido amplamente utilizado, pois pesquisas tem revelado que a divulgação de informações por pessoas mais próximas do público, tem sido mais eficiente para atingir positivamente os consumidores do que as propagandas divulgadas pelas próprias empresas (LU, CHANG; CHANG, 2014, WOOD; BURKHALTER, 2014).

Em relação ao Brasil, o Instagram, rede social em que são divulgados fotos e vídeos pelos participantes, tem sido o aplicativo mais utilizado pelos influenciadores digitais para divulgação. Esses formadores de opiniões reúnem um quantitativo de seguidores que se identificam de alguma forma com o seu perfil, seja em razão da beleza, da profissão, do estilo de vida, etc.

Alguns autores alegam que este fenômeno teve início no segmento de moda (FERNANDEZ, 2016), se espalhando depois para os demais ramos. Atualmente, dados provenientes de levantamento realizado por uma agência de mídia digital brasileira envolvendo dois jovens brasileiros, apontam que cerca de cinco milhões de pessoas seguem o humorista Felipe Neto e oito milhões seguem a atriz Kéfera Buchmann, em seus canais virtuais de interação (IINTERATIVA, 2016).

Nesse contexto, nota-se que a dinâmica publicitária, em especial via instagram, é demasiadamente forte no Brasil, onde influenciadores digitais, que pode ser desconhecido para

35 Id on Line Rev. Mult. Psic. V.12, N. 42, Supl. 1, p. 27-40, 2018 - ISSN 1981-1179 Edição eletrônica em http://idonline.emnuvens.com.br/id 
grande parte da população, mas altamente influente para um determinado grupo social, recebem produtos ou valores em troca da produção de postagem de divulgação.

O crescimento das redes sociais digitais tem sido um fator de colaboração pois permite uma maior dinâmica das informações. Assim, os digital influencers utilizam desses ambientes virtuais para criarem um engajamento maior com do corpo consumerista em relação ao bem ou serviço divulgado, despertando de forma mais eficiente os aspectos cognitivos, emocionais e comportamentais dos clientes em relação a marca (HOLLEBEEK; GLYNN; BRODIE, 2014).

Atualmente, o controle do público alvo pode ocorrer da seguinte forma:

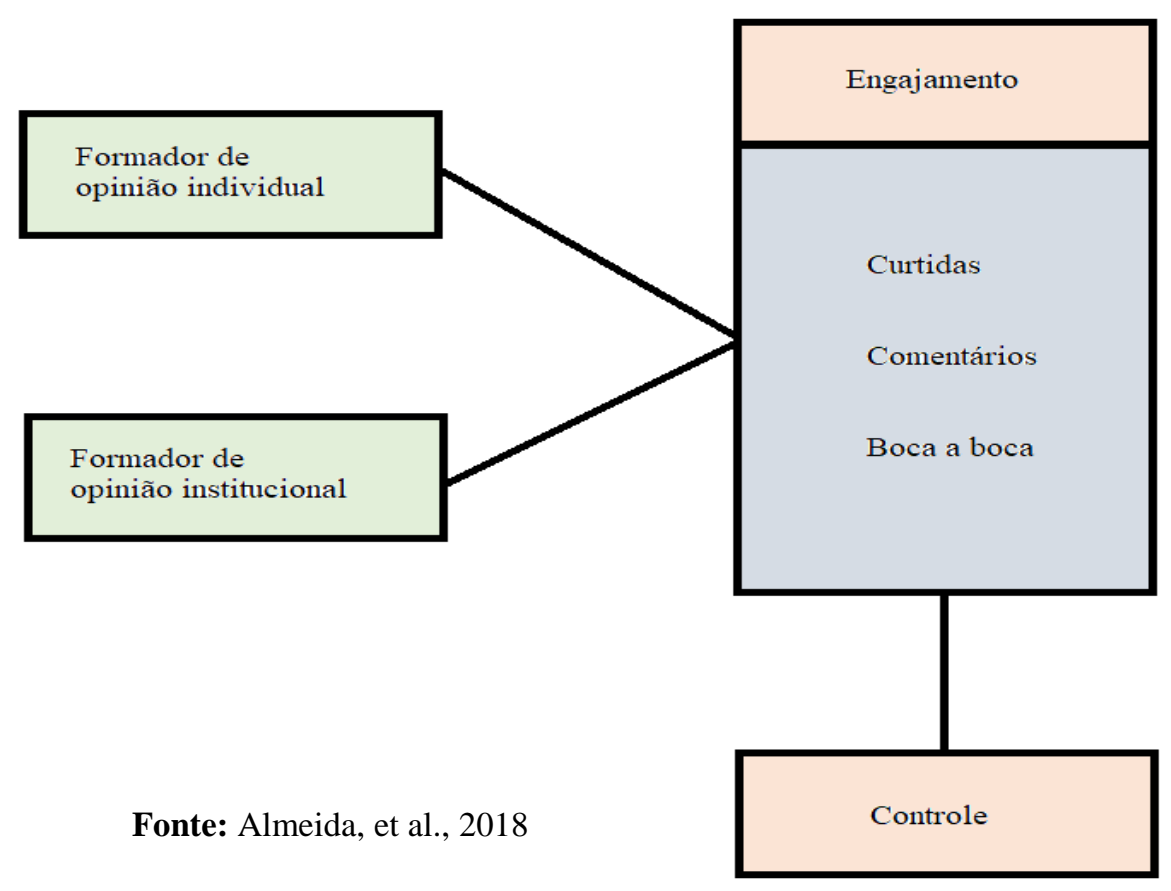

A maneira como se estruturam as redes sociais, oportunizam que as marcam possam atender aos mais diferentes objetivos e públicos, analisando se sua desenvoltura está sendo positiva ou negativa por meio da análise de "curtidas", comentários e marcações, que representam o "boca-a-boca" no plano virtual, verificando, dessa forma, o engajamento que o marketing digital está conferindo para sua marca.

Sendo assim, estudar esse fenômeno é de grande valia para a sociedade, tendo em vista que configura uma tática de marketing digital, pautado em um novo método fluxo comunicacional de baixo custo e alta disponibilidade, realizado com o uso de redes sociais virtuais (UZUNOGLU; KIP, 2014). 


\section{Considerações Finais}

As mídias digitais consistem em desafio a ser enfrentado pelas empresas, sendo necessário desenvolver novos métodos de marketing e interação com seus clientes para fins de acompanhar essa verdadeira revolução digital.

Conforme comentado, a hodierna era digital vem acompanhada de benefícios e diversos desafios ocasionados por tensões de mercado, que devem ser enfrentados pelas empresas, com vistas a manter ou melhorar a reputação de sua marca ou produto. Assim, nota-se que construir uma imagem positiva frente à clientela trata-se de missão difícil, sendo necessário desenvolver método eficaz para atingir determinado grupo de clientes de certo segmento, necessidades específicas e comportamentos semelhantes.

Tradicionalmente, as estratégias utilizadas de marketing e publicidade são desenvolvidas de forma dispendiosa, onde anúncios são meticulosamente elaborados cuidadosamente desenvolvidos com objetivo de construção ou manutenção da reputação da marca. Nesse caso, o sucesso ocorre quando se chama a atenção de um quantitativo considerável de pessoas do grupo alvo.

Nessa nova era de mídia digital e de expansão dos canais virtuais de comunicação, é preciso utilizar de métodos diferenciados para chamar a atenção dos consumidores, bem como para desenvolver uma perspectiva positiva da marca. Nesse cenário a solução plausível aponta no sentido das empresas investirem em profissionais especializados marketing digital, visto que estes saberão analisar dados digitais, controle de engajamento virtual, a estratégia de marketing adequada, dentre outros.

Outrossim, verifica-se que uma das fortes estratégias de marketing digital da atualidade envolve os digital influencers, onde esses indivíduos são capazes de apresentar informações sobre os produtos, recomendações de uso e comentários realistas e positivos, que provavelmente serão acatados por seus seguidores, uma vez que a divulgação realizada por uma pessoa mais "próxima" dos consumidores tem revelado ser mais eficaz do que propagandas elaboradas pela própria empresa. Essa comunicação personalizada que é realizada pelos influenciadores digitais gera uma certa confiança nos seguidores, e, consequentemente a disseminação das informações pelos indivíduos que os seguem.

37 Id on Line Rev. Mult. Psic. V.12, N. 42, Supl. 1, p. 27-40, 2018 - ISSN 1981-1179 Edição eletrônica em http://idonline.emnuvens.com.br/id 
Por fim, conclui-se que as empresas precisam investir no marketing digital para fins de acompanhar e se adequar à era digital que atualmente vivenciamos, sendo interessante a adoção das mídias sociais e nos digital influencers, tendo em vista que esses têm se revelado verdadeiros líderes de opinião, o que oportuniza a aplicação de estratégias de promoção de marcas e produtos e fortalecimento de relacionamento com os clientes.

\section{Referências}

ALBUQUERQUE, P.; PAVLIDIS, P.; CHATOW, U.; CHEN, K.Y.; JAMAL, Z. Evaluating promotional activities in an online two-sided market of user-generated content. Marketing Science, 31 (3), pp. 406-432, 2012.

ALMEIDA, M.I.S; COELHO, R.L.F, CAMILO JÚNIOR, C.G.; GODOY, R.M.F. Quem lidera sua opinião? Influência dos Formadores de opinião digitais no Engajamento. RAC Revista de Administracao Contemporanea. 22.1, January-February, p. 115, 2018.

CASTRO, I. V; SANTOS JÚNIOR, C. D. "O que gerencio e de quem dependo?": Determinantes da acao de blogueiros. Revista de Administracao Contemporanea, 19(4), 486507, 2015.

CHEN, Y.; FAY, S.; WANG, Q. The role of marketing in social media: How online consumer reviews evolve. Journal of Interactive Marketing, 25 (2), pp. 85-94, 2011.

CHEREDAR, T. At peak, Amazon sold a whopping 306 items per second in 2012. 2012. Disponível em: < https://venturebeat.com/2012/12/27/at-peak-amazon-sold-a-whopping-306items-per-second-in-2012/>. Acesso em 10/10/2018.

CLAY, K. A Amazon tem a melhor temporada de férias de todos os tempos, vendendo 306 itens por segundo. Website da Forbes, 2012. Disponível em: < https://www.forbes.com/sites/kellyclay/2012/12/27/amazon-has-best-holiday-season-everselling-306-items-per-second/\#6063a36c1e1f>. Acesso em: 08/10/2018.

DE VRIES, L; GENSLER, S; LEEFLANG, P.S.H. Popularity of brand posts on brand fan pages: An investigation of the effects of social media marketing. Journal of Interactive Marketing, 26 (2), pp. 83-91, 2012.

DHOLAKIA, UM; DURHAM, E. One café chain's Facebook experimente. Harvard Business Review, 88 (3) (2010), p. 26, 2010.

ECK VAN, P.S.; JAGER, W.; LEEFLANG, P.S.H. Opinion leaders' role in innovation diffusion: A simulation study. Journal of Product Innovation Management, 28 (2), pp. 187203, 2011. 
FLYNN, L.; GOLDSMITH, R. E.; EASTMAN, J. K. Opinion leaders and opinion seekers: Two new measurement scales. Journal of the Academy of Marketing Science, 24(2), 137-147, 1996.

GODES, D. SILVA, JC. Sequential and temporal dynamics of online opinion. Marketing Science, 31 (3), pp. 448-473, 2012.

HOFFMAN, D. L.; NOVAK, T. P. Marketing in hypermedia computer-mediated environments: Conceptual foundations. Journal of Marketing, 60(3), 50-68, 1996.

HOLLEBEEK, L. D.; GLYNN, M. S.; BRODIE, R. J. Consumer brand engagement in social media: Conceptualization, scale development and validation. Journal of Interactive Marketing, 28(2), 149-165, 2014.

HUSSON, T.; ASK, J.A.; OVERBY, C.C.; PARRISH, M.; MULLEN, A.; MCCARTHY, J.C.; ROBERGE, D.; KWAN, E. 2013 Mobile trends for marketers. Forrester, 2013. Disponível em: < https://go.forrester.com/blogs/13-02-142013_mobile_trends_for_marketers/>. Acesso em: 08/10/2018.

IINTERATIVA. Infográfico--Por que investir em influenciadores digitais? Disponível em: $<\quad$ http://www.iinterativa.com.br/infografico-por-investir-em-influenciadores-digitais/>. Acesso em: 08/10/2018.

KAPLAN, M.; HAENLEIN, M. Users of the World Unite. The Challenges and Opportunities of Social Media, Business Horizons, 53, pp. 59-68, 2010.

KEE, R. The sufficiency of product and variable costs for production-related decisions when economies of scope are present. International Journal of Production Economics, 114 (2), pp. 682-696, 2008.

KUMAR, V.; GUPTA, S. Conceptualizing the evolution and future of advertising. Journal of Advertising, 45(3), 302-317, 2016.

LU, L.; CHANG, W.; CHANG, H. Consumer attitudes toward blogger's sponsored recommendations and purchase intention: The effect of sponsorship type, product type, and brand awareness. Computers in Human Behavior, 34, 258-266, 2014.

LUSCH, R. F. Marketing's evolving identity: defining our future. Journal of Public Policy \& Marketing, 26(2), p. 261-268, 2007.

MANCHANDA, P; DUBÉ, J.P.; GOH, K.Y.; CHINTAGUNTA, P.K. The effect of banner advertising on Internet purchasing. Journal of Marketing Research, 43 (1), pp. 98-108, 2006. MAYZLIN, D; YOGANARASINHAN, H. Link to success: How blogs build an audience by promoting rivals. Management Science, 58 (9), pp. 1651-1668, 2012. 
SORESCU, A; FRAMBACH, RT; SINGH， J; RANGASWAMY， A; BRIDGES, C. Innovations in retail business models. Journal of Retailing, 87S (1), pp. 3-16, 2011.

SCHULTZ, D. The future of advertising or whatever we're going to call it. Journal of Advertising, 45(3), 276-285, 2016.

UZUNOGLU, E.; KIP, S. M. Brand communication through digital influencers: Leveraging blogger engagement. International Journal of Information Management, 34(5), 592- 602, 2014.

VAN DOORN, J; LEMON, KN; MITTAL, V; NASS, S; PICK, D; PIRNER, P; VERHOEF, PC. Customer engagement behavior: theoretical foundations and research directions. Journal of Service Research, 13 (3), pp. 253-266, 2010.

VARGO, S. L.; LUSCH, R. F. Evolving to a new dominant logic for marketing. Journal of Marketing, 68(1), p. 1-17, 2004.

VERHOEF, P.C.; BECKERS, S.F.M.; VAN DOORN, J. Understand the perils of cocreation. Harvard Business Review, 91 (9), p. 28, 2013.

VERHOEF, P.C.; REINARTZ, W.J.; KRAFFT, M. Customer engagement as a new perspective in customer management. Journal of Service Research, 13 (3), pp. 247-252, 2010.

WILKIE, W. L.; MOORE, E. S. Scholarly research in marketing: Exploring the "4 eras" of thought development. Journal of Public Policy \& Marketing, 22(2), p. 116-146, 2003.

WOOD, N. T.; BURKHALTER, J. N. Tweet this, not that: A comparison between brand promotions in microblogging environments using celebrity and company-generated tweets. Journal of Marketing Communications, 20(1/2), 129-146, 2014.

ZHANG, K; EVGENIOU, T; PADMANABHAN, V; RICHARD, E. Content contributor management and network effects in a UGC environment. Marketing Science, 31 (3), pp. 433-447, 2012.

Como citar este artigo (Formato ABNT):

SANT'ANNA, André Luis. Marketing digital e os digital influencers: Breves comentários acerca dessa ferramenta e de sua eficácia na divulgação de bens e serviços. Id on Line Rev.Mult. Psic., 2018, vol.12, n.42, Supl. 1, p. 27-40. ISSN: 1981-1179.

Recebido: 04/10/2018;

Aceito: $17 / 10 / 2018$ 